\title{
Evaluation of Antibacterial Effects of Bile Salt on Pathogenic Bacteria- An in vitro Study
}

\author{
Anuradha Tyagi*, Vanita Gupta and Aseem Bhatnagar \\ Department of Capacity Enhancement \& Product Implementation, Institute of Nuclear \\ Medicine and Allied sciences, Brig S. K. Mazumdar Road, Delhi-110054, India
}

*Corresponding author

\section{A B S T R A C T}

Keywords

Bile salt, E. coli, $S$. aureus,

Antimicrobial

\section{Article Info}

Accepted:

17 September 2019

Available Online:

10 October 2019

\begin{abstract}
Antibiotics are the first line of defence against bacterial infections. Overuse/misuse of antibiotics has led to the emergence of antibiotics resistant bacterial strains, making them ineffective. Alternative approaches should be sought to handle this challenge. Bile salt is a cation compounded form of bile acid and is synthesized in the liver. Reduction in the flow of bile salts has led to bacterial translocation in the body. Therefore, the aim of the present study was to evaluate the in vitro effect of bile salt on E. coli and S. aureus. This work also investigated the additive effect of bile salt in combination with other antibiotics namely gentamycin and ciprofloxacin. Bile salt exhibited maximum zone of inhibition (ZI) of $4.8 \pm 0.28 \mathrm{~mm}$ against $E$. coli while against $S$. aureus, $12.0 \pm 0 \mathrm{~mm} \mathrm{ZI}$ was observed. While exploring the additive effect of bile salt, it enhanced the ZI of gentamycin and ciprofloxacin against both the microorganisms. Bile salt was also found effective in damaging the cell membrane of $S$. aureus which was evident by nucleic acid and protein leakage. This effect remained absent with $E$. coli. Thus, bile salt showed significant antibacterial activity against gram-positive microorganism while gram-negative remained resistant. Bile salt also exhibited additive effect in combination with gentamycin and ciprofloxacin.
\end{abstract}

\section{Introduction}

Antibiotics are the medications that are used to destroy or slow down the growth of bacteria. The uncontrolled improper use of antibiotics for treatment of bacterial infections has led to the emergence of antibiotic resistant strains and is becoming an issue of global concern. Thus, there is an urgent need to investigate new agents having antibacterial properties to combat the issue of antibiotic resistance. In the last decade, no new antibiotic has come up due to slow drug discovery. Since the development of new antibiotic is complicated and difficult process, so augmentation of present antibiotics might be a one of the strategies (Khoshnood et al., 2017).

There are various natural and synthetic compounds which contain antimicrobial properties; these non-antibiotic agents may 
have a direct antibacterial activity or augment the effect of antibiotics losing its property.

Therefore, these agents might be a strategy to modify the bacterial metabolism and act additively or synergistically with already existing antibiotics (Martins et al., 2008).

Bile salts are synthesized in the liver from cholesterol, conjugated with glycine or taurine and secreted in bile with cholesterol and lecithin (Cowen et al., 1977). It is a biological detergent and plays an important role in maintaining intestinal microbiome. Alterations in the level of bile salts can lead to increased colonization by pathogens.

In previous studies, bile salt showed antibacterial activity against biliary pathogenEnterococcus fecalis (Sung et al., 1993). Bile salts inhibited bioenergetic process by intracellular acidification and dissipation of the proton motive force (Kurdi et al., 2006). They are known to cause induction of DNA damage and protein denaturation (Merritt and Donaldson, 2009). Bile salts were reported to help in reducing endotoxemia in obstructive jaundice patients (Cahill et al., 1987).

In animal models, cholestasis leads to structural changes in the enterocytes which is associated with bacterial translocation (Lorenzo-Zuniga et al., 2003) which may further lead to sepsis (Wiest et al., 2014). It was reported that oral supplementation of bile salts in cirrohitic rats can prevent small intestinal bacterial overgrowth and translocation (Lorenzo-Zuniga et al., 2003).

Therefore, the aim of the current study was to evaluate the in vitro effect of bile salt alone and in combination with existing antibiotics (gentamycin and ciprofloxacin) against the selected test microorganism (E. coli and $S$. aureus).

\section{Materials and Methods}

\section{Chemicals}

Bile salt was obtained from Sigma-Aldrich ( $\mathrm{St}$ Louis, MO, USA). Ciprofloxacin and gentamycin were purchased from Titan chemicals, India. Muller Hinton ( $\mathrm{MH})$ broth, Nutrient broth and Agar were purchased from Himedia, Mumbai, India. Bacterial cultures Escherichia coli (MCC2412) and Staphylococcus aureus (NCC2043) were obtained and maintained as stock culture in the laboratory.

\section{Antimicrobial sensitivity test}

Antimicrobial susceptibility of all bacterial strains was determined following the disc agar diffusion method. The bacterial strains were cultured overnight, diluted in $\mathrm{MH}$ broth to a McFarland turbidity of $0.5\left[10^{8}\right.$ colony forming unit $(\mathrm{CFU}) / \mathrm{ml}$ ] and then seeded on $\mathrm{MH}$ agar plates. Sterile discs $(6 \mathrm{~mm})$ containing different concentrations of bile salt were placed on the inoculated agar plates. After incubation for 24 hours at $37^{\circ} \mathrm{C}$, the zone of inhibition (ZI) was measured. Further, to evaluate the additive effect of bile salt, two standard antibiotics namely gentamycin $(10 \mu \mathrm{g} / \mathrm{disc})$ and ciprofloxacin $(5 \mu \mathrm{g} / \mathrm{disc})$ were used in combination with bile salt against $E$. coli and $S$. aureus. The antibiotic discs were further impregnated with different concentrations of bile salt and placed on agar plates containing bacterial culture. The ZI was measured and interpreted after completion of incubation period.

\section{Measurement of nucleic acid and protein leakage}

Bacterial cells were cultured and treated with different concentrations of bile salt, and samples were collected over a time course of 30, 60, 90, 120, and 150 minutes. The 
suspension was centrifuged at $8000 \mathrm{x}$ g for 10 minutes and then the supernatant was filtered using a $0.22 \mu \mathrm{m}$ pore size membrane filter. Leakage of nucleic acids and proteins upon treatment with the bile salt were monitored by measuring 260 and $280 \mathrm{~nm}$ absorbance in the culture medium respectively in a Biogentek Microplate reader.

\section{Results and Discussion}

The current study illustrated the effect of bile salt on two microorganisms- E. coli and $S$. aureus. Antimicrobial sensitivity of bile salt showed that bile salt possesses antimicrobial activity against the $S$. aureus in disc diffusion method. The study revealed that bile salt exerted its antimicrobial effect in a dose dependent manner against $S$. aureus with a maximum ZI of $13.6 \pm 0 \mathrm{~mm}$. However, bile salt remains non-effective against $E$. coli. Bile salt exhibited ZI ranging from $3.2 \mathrm{~mm}$ to $5 \mathrm{~mm}$ against E. coli (Table 1) while in case of $S$. aureus the ZI ranges from $5.1 \mathrm{~mm}$ to $13.6 \mathrm{~mm}$ (Table 2). Thus, the results indicated that bile salt showed antimicrobial properties against gram positive bacteria only. To evaluate the additive effect of bile salt, it was used in combination with antibiotics namely gentamycin $(10 \mu \mathrm{g})$ and ciprofloxacin $(5 \mu \mathrm{g})$. Using disc diffusion method, it was observed that bile salt increased the ZI of gentamycin and ciprofloxacin, against E. coli (Table 1). Similar effect was observed when bile salt and antibiotics combination was used against $S$. aureus (Table 2).

Nucleic acid and protein leakage was studied to evaluate the effect of bile salt on cell membrane. Nucleic acid content is directly proportional to the O.D value at $260 \mathrm{~nm}$. Thus, leakage of nucleic acid was measured at $260 \mathrm{~nm}$ and found to increased in comparison to negative control (0.9\% saline) (Fig. 1) in case of both microorganisms. However, in case of E. coli, the increase in leaked nucleic acid was not significant. Similarly, leakage of cellular protein $(280 \mathrm{~nm})$ was only observed in $S$. aureus treated with bile salt. A significant $(\mathrm{p}<0.01)$ increase in protein content was observed upon exposure to bile salt (Fig. 2). The UV absorbance value increased with time of exposure to bile salt. Bile salt remained ineffective to bind and disturb the cell membrane integrity of E. coli and thus, nonsignificant protein content was found.

Bile salts are synthesized in the liver from cholesterol. They are cation compounded form of bile acid and are amphipathic in nature. The data of the current study indicates that bile salt has inhibitory action on the growth of $S$. aureus and $E$. coli remain ineffective to the action of bile salts. The cell wall composition of gram negative bacterium $E$. coli became a barrier for bile salt to invade and show its action against $E$. coli. Previous studies also reported the efflux of bile salt chenodeoxycholate by E. coli (Thanassi et al., 1997). Both E. coli and S. aureus are commensal bacterium and human pathogens. E. coli is most frequently responsible for urinary tract infections whereas $S$. aureus is leading cause of bacteremia and infective endocarditis. The effect of bile salt on the growth of microorganisms was also reported in prior studies. Sung et al., 1993 showed that hydrophobic bile salts played a role of growth inhibitor against E. coli and E. fecalis. Sannasidappa et al., 2017 found that unconjugated bile salts possess more potent antibacterial properties against $S$. aureus in comparison to conjugated bile salts.

Our study showed that the use of bile salt accelerated the action of some of the antibiotics (gentamycin and ciprofloxacin). Previously, bile salt was reported to increase the solubility of rifaximin and thus enhanced its antibacterial effect (Darkoh et al., 2010). Oxgall bile salts enhanced cell envelope permeability circumvented the lack of 
cytochrome-driven antibiotic uptake, thereby changing aminoglycoside susceptibility (Elkins and Mullis, 2004). Oxgall bile salt also changed intrinsic resistance of most lactobacilli (and some bifidobacteria) to polymyxin $\mathrm{B}$, by cell membrane disruption (Charteris et al., 2000).

Table.1 Antimicrobial activity of bile salt alone and in combination with gentamycin and ciprofloxacin using disc diffusion method against $E$. coli

\begin{tabular}{|c|c|c|c|}
\hline \multicolumn{4}{|c|}{ Zone of Inhibition (mm) } \\
\hline BS (mM) & $\begin{array}{c}\text { ZI by bile } \\
\text { salt alone }\end{array}$ & $\begin{array}{c}\text { Gentamycin } \\
(\mathbf{1 0} \boldsymbol{\mu} \mathbf{)}+\mathbf{B S}\end{array}$ & $\begin{array}{c}\text { Ciprofloxacin } \\
\mathbf{( 5 \mu g ) + ~ B S ~}\end{array}$ \\
\hline $\mathbf{0}$ & 0 & $9.0 \pm 0.2$ & $10+0.05$ \\
\hline $\mathbf{1}$ & $3.2 \pm 0.14$ & $9.0 \pm 0.1$ & $10 \pm 0.1$ \\
\hline $\mathbf{2}$ & $4.9 \pm 0.14$ & $9.0 \pm 0.25$ & $10 \pm 0.11$ \\
\hline $\mathbf{5}$ & $4.8 \pm 0.14$ & $8.5 \pm 0.36$ & $11 \pm 0.14$ \\
\hline $\mathbf{1 0}$ & $4.9 \pm 0.28$ & $10 \pm 0.05$ & $12.5 \pm 0.25$ \\
\hline $\mathbf{1 5}$ & $5 \pm 0.07$ & $12 \pm 0.05$ & $13.2 \pm 0.2$ \\
\hline $\mathbf{2 0}$ & $4.8 \pm 0.28$ & $12.1 \pm 0$ & $13.1 \pm 0.22$ \\
\hline
\end{tabular}

Data are mean of 3 independent experiments

BS- Bile salt

ZI- Zone of inhibition

Table. 2 Antimicrobial activity of bile salt alone and in combination with gentamycin and ciprofloxacin using disc diffusion method against $S$. Aureus

\begin{tabular}{|c|c|c|c|}
\hline \multicolumn{4}{|c|}{ Zone of Inhibition $(\mathbf{m m})$} \\
\hline BS $(\mathbf{m M})$ & $\begin{array}{c}\text { ZI by bile } \\
\text { salt alone }\end{array}$ & $\begin{array}{c}\text { Gentamycin } \\
(\mathbf{1 0} \boldsymbol{\mu g})+\mathbf{B S}\end{array}$ & $\begin{array}{c}\text { Ciprofloxacin } \\
\mathbf{( 5} \boldsymbol{\mu g})+\mathbf{B S}\end{array}$ \\
\hline $\mathbf{0}$ & 0 & $12.0 \pm 0.0$ & $13.0 \pm 0.12$ \\
\hline $\mathbf{1}$ & $5.1 \pm 0.14$ & $12.0 \pm 1.2$ & $13.0 \pm 0.22$ \\
\hline $\mathbf{2}$ & $5.4 \pm 0.28$ & $12.1 \pm 0.5$ & $13.0+0.5$ \\
\hline $\mathbf{5}$ & $7.0 \pm 0.14$ & $12.23 \pm 0.29$ & $13.2 \pm 0.01$ \\
\hline $\mathbf{1 0}$ & $10.1 \pm 0.14$ & $13.0 \pm 0.25$ & $14.1 \pm 0.26$ \\
\hline $\mathbf{1 5}$ & $13.5 \pm 0.41$ & $14.5 \pm 0.05$ & $16.0 \pm 0.26$ \\
\hline $\mathbf{2 0}$ & $13.6 \pm 0.0$ & $15.8 \pm 0.25$ & $16.0 \pm 0.22$ \\
\hline
\end{tabular}

Data are mean of 3 independent experiments BS- Bile salt

ZI- Zone of inhibition 
Fig.1 Measurement of cellular leakage of nucleic acid from (A) E. coli and (B) S. aureus upon exposure to bile salt. Cell density of $10^{8} \mathrm{CFU} / \mathrm{ml}$ was treated with $20 \mathrm{mM}$ of bile salt. UCUntreated control. Data is presented as mean \pm S.E of 3 independent experiments. ${ }^{*} \mathrm{p}<0.01$ significant in comparison to UC
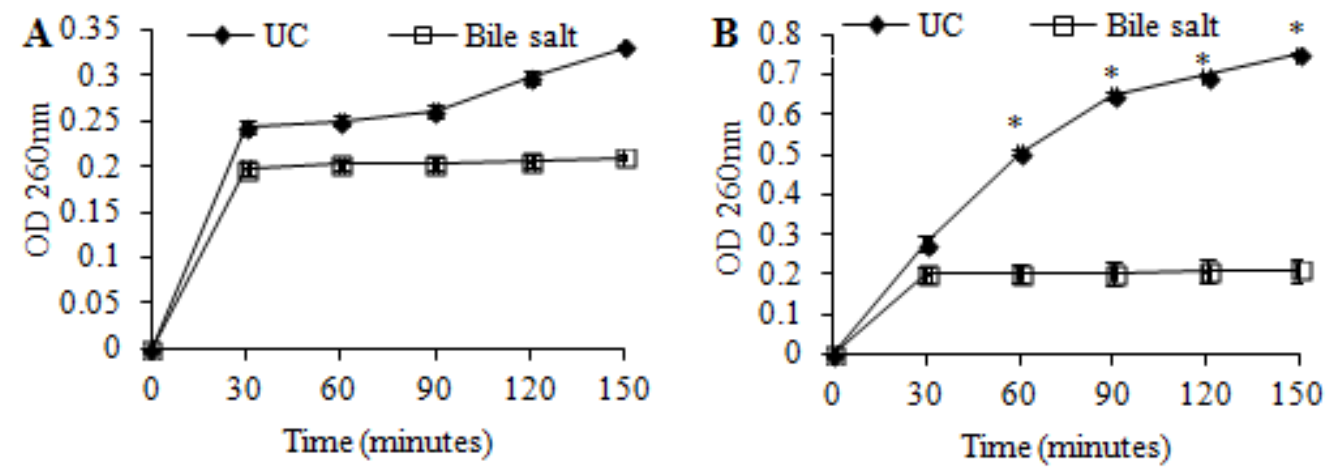

Fig.2 Measurement of leakage of cellular protein from (A) E. coli and (B) S. aureus upon exposure to bile salt. Cell density of $10^{8} \mathrm{CFU} / \mathrm{ml}$ was treated with $20 \mathrm{mM}$ of bile salt. UC- Untreated control. Data is presented as mean \pm S.E of 3 independent experiments. ${ }^{*} p<0.01$ significant in comparison to UC

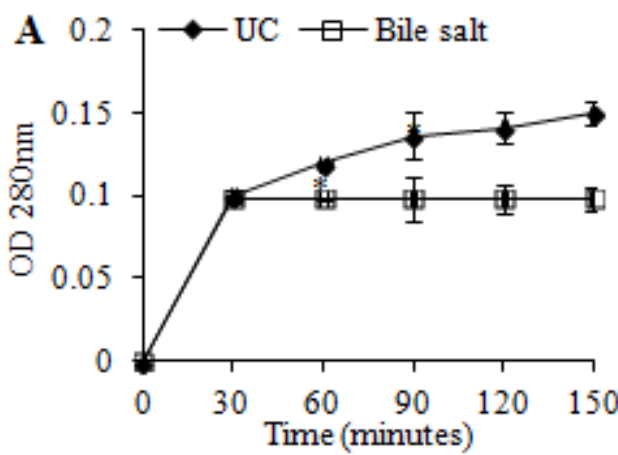

Bile salt plays an important role in the internal defense mechanisms of the body. It helps in maintaining indigenous microbiota and protects against enteric pathogens in the intestine (Sung et al., 1993; Itoh et al., 1999). Reduced levels of bile salts in the intestine correlate with cases of bacterial overgrowth and translocation in the small intestine, leading to endotoxemia in cirrhotic rats (Lorenzo-Zuniga et al., 2003). Being amphiphatic, bile salt contains hydrophilic as well as hydrophobic structural components. Due to their detergent nature, bile salt exerts

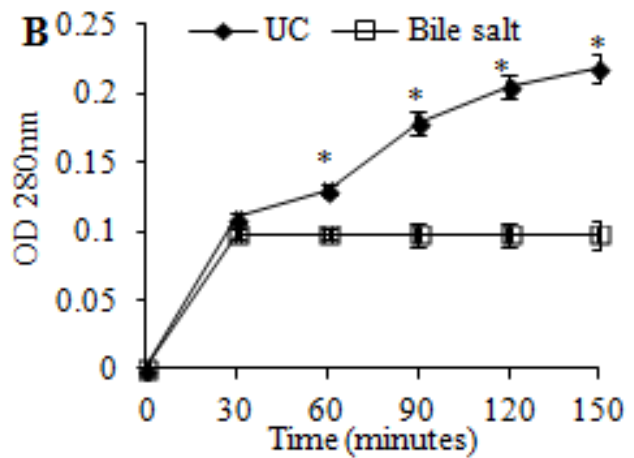

its effect on cell membrane by lysing them or by inducing cell death pathway (Perez and Briz, 2009). In our study also, the leakage of nucleic acid and protein (Fig. 1 and 2) could be attributed due to cell membrane lysis. Bile salt can rapidly dissolve integral membrane lipids and cause dissociation of integral membrane proteins (Coleman et al., 1980). Due to these features, bile salts has been used for treatment of various clinical conditions such as in case of severe steatorrhea (Fordtran et al., 1982), psoriasis (Gyuresovics and Bertok, 2003), and prevention of postoperative 
renal failure in patients with obstructive jaundice (Cahil, 1983).

Bile salt has significant antimicrobial activity against gram positive bacteria with a potential. additive effect when used in combination with either gentamycin or ciprofloxacin. Herein, further studies are warranted to elucidate the main mechanism of additive action of bile salt in combination with specific antibiotics.

\section{References}

Cahill, C.J. 1983. Prevention of postoperative renal failure in patients with obstructive jaundice- the role of bile salts. BJS, 70(10): 590-95.

Cahill, C.J., Pain, J.A., Bailey, M.E. 1987. Bile salts, endotoxin and renal function in obstructive jaundice. Surg Gynecol Obstet. 165(6):519-22.

Charteris, W.P., Kelly, P.M., Morelli, L., Collins J.K. 2000. Effect of Conjugated Bile Salts on Antibiotic Susceptibility of Bile Salt-Tolerant Lactobacillus and Bifidobacterium isolates. Journal of Food Protection, 63(10): 1369-1376.

Coleman, R., Lowe, P.J., Billington. D. 1980. Membrane lipid composition and susceptibility to bile salt damage. Biochim. Biophys. Acta, 599(1): 294300.

Cowen, A.E., Campbell, C.B. 1977. Bile salt metabolism. I. The physiology of bile salts. Aust N Z J Med. 7(6): 579-86.

Darkoh, C., Lichtenberger, L.M., Ajami, N., Dial, E.J., JIANG, Z., Dupont, H.L. 2010. Bile Acids Improve the Antimicrobial Effect of Rifaximin. Antimicrobial Agents and Chemotherapy, 54(9): 3618-3624.

Elkins, C.A., Mullis, L. B. 2004. Bilemediated aminoglycoside sensitivity in Lactobacillus species likely results from increased membrane permeability attributable to cholic acid. Appl. Environ. Microbiol. 70(12): 72007209.

Fordtran, J.S., Bunch, F., Davis, G.R. 1982. Ox Bile Treatment of Severe Steatorrhea in an Ileectomy-Ileostomy Patient. Gastroenterology, 82(3):564-8.

Gyurcsovics, K., Bertók, L. 2003. Pathophysiology of psoriasis: coping endotoxins with bile acid therapy. Pathophysiology, 10(1): 57-61.

Itoh, M., Wada, K., Tan, S., Kitano, Y., Kai. J., Makino, I. 1999. Antibacterial action of bile acids against helicobacter pylori and changes in its ultrastrural morphology: effect of unconjugated dihydroxy bile acid. J. Gastroenterol., 34(5): 571-576.

Khoshnood, S., Heidary, M., Mirnejad, R., Bahramian, A., Sedighi, M., Mirzaei, H. 2017. Drug-resistant gram-negative uropathogens: A review. Biomed Pharmacother, 94, 982-94.

Kurdi, P., Kawanishi, K., Mizutan, K., Yokota, A. 2006. Mechanism of growth inhibition by free bile acids in Lactobacilli and Bifidobacteria. Journal of Bacteriology, 188 (5):19791986.

Lorenzo-zuniga, V., Bartoli, R., Planas, R., Hofmann, A.F., Vinado, B., Hagey, L. R., Hernández. J.M., Mañé, J., Alvarez. M.A., Ausina, V., Gassull. M.A. 2003. Oral bile acids reduce bacterial overgrowth, bacterial translocation, and endotoxemia in cirrhotic rats. Hepatology 37(3): 551557.

Merritt M.E., Donaldson. J.R. 2009. Effect of bile salts on the DNA and membrane integrity of enteric bacteria. J. Med. Microbiol. 58(12): 1533-1541.

Perez, M.J., Briz. O. 2009. Bile acid induced cell injury and protection. World Journal of Gastroenterology. 15(14): 
1677-1689.

Prieto, A.I., Ramos-morales, F., Casadesus. J. 2004. Bile-induced DNA damage in Salmonella enterica. Genetics, 168(4): 1787-1794.

Sannasiddappa, T.H., Lund, P.A., Clarke S.R. 2017. In vitro antibacterial activity of unconjugated and conjugated bile salts on Staphylococcus aureus. Frontiers in Microbiology, 8, 1581.

Sung, J.Y., Shaffer, E.A., Costerton, J.W. 1993. Antibacterial activity of bile salts against common biliary pathogens. Effects of hydrophobicity of the molecule and in the presence of phospholipids. Dig Dis Sci., 38(11) : 2104-12.

Thanassi D G, Cheng L W, Nikaido H. 1997. Active efflux of bile salts by Escherichia coli. J bacteriol., 179(8): 2512-2518.

Wiest, R., Lawson, M., Geuking, M. 2014. Pathological bacterial translocation in liver cirrhosis. J Hepatol., 60(1):197209.

\section{How to cite this article:}

Anuradha Tyagi, Vanita Gupta and Aseem Bhatnagar. 2019. Evaluation of Antibacterial Effects of Bile Salt on Pathogenic Bacteria- An in vitro Study. Int.J.Curr.Microbiol.App.Sci. 8(10): 2430-2436. doi: https://doi.org/10.20546/ijcmas.2019.810.282 